\title{
Correction to: Dissociating motor learning from recovery in exoskeleton training post- stroke
}

Nicolas Schweighofer ${ }^{1 *}$, Chunji Wang ${ }^{2}$, Denis Mottet ${ }^{3}$, Isabelle Laffont ${ }^{4}$, Karima Bakhti ${ }^{4}$,

David J. Reinkensmeyer ${ }^{5}$ and Olivier Rémy-Néris ${ }^{6}$

\section{Correction to: J Neuroeng Rehabil https://doi.org/10.1186/s12984- \\ 018-0428-1}

The original article [1] contained an error whereby the co-author, Karima Bakhti's name was displayed incorrectly. This error has now been corrected.

\begin{abstract}
Author details
'Biokinesiology and Physical Therapy, University of Southern California, Los Angeles, USA. ${ }^{2}$ Neuroscience graduate Program, University of Southern California, Los Angeles, USA. ${ }^{3}$ STAPS, Université de Montpellier, Euromov, Montpellier, France. ${ }^{4}$ Montpellier University Hospital, Euromov, IFRH, Montpellier University, Montpellier, France. ${ }^{5}$ Departments of Mechanical and Aerospace Engineering, Anatomy and Neurobiology, University of California, Irvine, USA. 'Université de Bretagne Occidentale, Centre hospitalier universitaire, LaTIM-INSERM UMR1 101, Brest, France.
\end{abstract}

Received: 4 December 2018 Accepted: 7 December 2018

Published online: 17 December 2018

\section{Reference}

1. Schweighofer $\mathrm{N}$, et al. Dissociating motor learning from recovery in exoskeleton training post-stroke. J Neuroeng Rehabil. 2018;15:89. https://doi. org/10.1186/s12984-018-0428-1.

\footnotetext{
* Correspondence: schweigh@usc.edu

'Biokinesiology and Physical Therapy, University of Southern California, Los Angeles, USA

Full list of author information is available at the end of the article
} 